\title{
Marcação de aspecto gramatical nos verbos de ligação: uma análise morfológica
}

\author{
Gláucia do Carmo Xavier* \\ Kelly Cesário de Oliveira**
}

\section{Resumo}

Este artigo tem por objetivo apresentar uma análise morfológica dos verbos de ligação (VL) para verificação da marcação aspectual nessa tipologia verbal. O texto toma como amostra os verbos ser, estar, continuar, virar, andar, ficar, parecer, permanecer, viver, tornar-se e encontrar-se. Em uma continuidade da investigação para a construção da natureza sintática dos VL, este estudo apresenta uma análise morfêmica, por meio da apresentação de quadros morfológicas e análise do aspecto gramatical dos VL. A abordagem metodológica utilizada foi a pesquisa bibliográfica e análise morfêmica do radical e desinência modo, tempo e aspecto (DMTA). Os resultados demonstraram que os VL podem apresentar conteúdo semântico.

Palavras-chave: Verbos de ligação. Aspecto gramatical. Tabela morfológica. Conteúdo semântico.

\footnotetext{
* Instituto Federal de Minas Gerais (IFMG). Pós-Doutora pela Universidade Federal Fluminense (UFF), Doutora em Linguística e Língua Portuguesa pela PUC Minas, Mestre em Educação pela PUC Minas, Especialista em Psicopedagogia Clínica e em Psicopedagogia Institucional, Professora de Língua Portuguesa e Literatura. Orcid: https://orcid.org/0000-0003-3133-7354.

* Universidade Federal de Minas Gerais (UFMG). Mestranda do Programa de Pós-Graduação em Estudos Linguísticos, Bolsista da Fundação de Amparo à Pesquisa do Estado de Minas Gerais (Fapemig). Orcid: https://orcid.org/0000-0002-6262-5976.
} 


\title{
Grammatical aspect marking in linking verbs: a morphological analysis
}

\begin{abstract}
This article aims to present a morphological analysis of linking verbs (LV) to verify the aspectual marker in this verbal typology. The text takes as sample the Brazilian Portuguese linking verbs ser, estar, continuar, virar, andar, ficar, parecer, permanecer, viver, tornar-se and encontrar-se. Continuing the investigation for the construction of the syntactic nature of LV, this study presents a morphemic analysis through the presentation of morphological frames and analysis of the grammatical aspect of LV. The methodological approach consisted of bibliographic research, as well as morphemic analysis of the roots and the mood, tense, and aspect inflection. The results showed that the VL may have semantic content.
\end{abstract}

Keywords: Linking verbs. Grammatical aspect. Morphological chart. Semantic content.

Recebido em: 28/03/2020

Aceito em: 11/07/2020 


\section{Considerações iniciais}

O estudo sobre os verbos de ligação (VL) tem se tornado cada vez mais relevante, principalmente quando se trata da natureza sintática dessa categoria verbal, uma vez que, comumente, os VL têm sido comparados aos verbos de alçamento, copulares e/ou inacusativos, conforme atestado por Xavier, Kenedy e Oliveira (2018). Este estudo, que se insere em uma pesquisa maior de cunho gerativista (CHOMSKY, 1995), reconhece a complexidade em construir uma teoria próxima ao consenso sobre a natureza sintática dos verbos de ligação (VL) e por isso apresenta esta investigação que objetiva compreender a marcação de aspecto dos VL.

Xavier, Kenedy e Oliveira ${ }^{1}$ (2018) debruçaram-se sobre questões sintáticas de identidade do VL que ocasionaram a necessidade de esse verbo ser reconhecido como identidade única, por apresentar traços sintáticos independentes e não ser conceituado como sinônimo de verbos de alçamento, copulares e/ ou inacusativos. Os autores, em sequência, buscaram apresentar a representação sintática dos VL, já que estes apresentam uma natureza sintática que difere da dos verbos monoargumentais e biargumentais, pois os VL não selecionam argumentos, mas uma small clause, e isso demanda uma estrutura sintática particular para representar a derivação da sentença. Essa estrutura, que será apresentada mais adiante, não apresenta sintagma verbal, já que o sintagma aspectual supre as necessidades no momento da derivação da sentença e pelo fato de o VL não selecionar argumentos.

Devido aos resultados da pesquisa citada acima, este artigo apresenta, agora, o terceiro momento do estudo que tratou sobre 
aspecto do VL, utilizando sempre a mesma amostra de VL: ser, estar, continuar, virar, andar, ficar, parecer, permanecer, viver, tornar-se e encontrar-se. Para delimitar o foco da investigação, as pesquisadoras optaram, nessa fase, por verificar se a marcação aspectual faz do VL um verbo semanticamente preenchido, indo de encontro ao afirmado por Sanchez-Mendes (2014, p. 173) de que o VL é "semanticamente vácuo e não é considerado na computação semântica".

Como objetivos específicos, este estudo se propôs a (i) apresentar quadros morfológicos que apontassem possíveis expressões de aspecto gramatical pelo VL do Português Brasileiro (PB); (ii) identificar se VL descreve situações apenas com marcação de tempo ou também de aspecto; e (iii) determinar o papel dos radicais dos VL na marcação de aspecto gramatical. Neste momento, esta pesquisa, para além dos pressupostos da Teoria Gerativa, considerou análises morfológicas utilizadas na categorização morfêmica dos verbos pela Gramática Descritiva, de forma especial, na seção 4 deste texto.

Desdobrando a categoria aspectual, é preciso fazer uma breve elucidação sobre conceitos-chave para o estudo dessa categoria. Castilho (1968, p. 14) define aspecto como "visão objetiva da relação entre o processo e o estado expressos pelo verbo e a ideia de duração ou desenvolvimento", ou seja, aspecto diz respeito aos processos internos ao verbo. Comrie (1976) complementa o entendimento do aspecto como uma categoria responsável pela constituição temporal interna da situação e, pode-se dizer também, pelos processos internos do sintagma verbal. Nesse viés, é necessário acentuar que a categoria aspectual pode ser analisada sob duas óticas, do aspecto gramatical e do aspecto lexical, este último também denominado de aspecto semântico. 
Em relação ao aspecto gramatical, tem-se o aspecto imperfectivo, caracterizado por uma ação não acabada, como em

(1) Liza parecia cansada;

E o aspecto perfectivo, caracterizado por uma ação acabada, como

(2) João virou a noite acordado na casa do amigo.

Já para o aspecto semântico, há a classificação de seis traços: télico/atélico, durativo/pontual e dinâmico/estativo, que estão sendo estudados, porém serão demonstrados em outro trabalho.

Este artigo está organizado da seguinte maneira: em um primeiro momento, as autoras remetem-se à apresentação da categoria aspectual para apresentar as características do aspecto gramatical, assim como do aspecto semântico. Posteriormente, há a descrição metodológica adotada na investigação e, por conseguinte, na quarta seção, a análise morfêmica do VL por meio de quadros morfológicas e análise do aspecto gramatical. Por fim, nas considerações finais, é demonstrada a influência dos traços de aspecto gramatical para a interpretação aspectual do VL. Admite-se, entretanto, que as reflexões sobre a temática central estão diluídas ao longo do texto, são processuais e, por isso, não se concentram apenas na quinta seção, destinada às conclusões.

\section{A categoria aspectual}

Nesta seção, será abordada a categoria aspectual, que é, frequentemente, comparada com a categoria de tempo. Essa comparação não é gratuita, afinal, essas categorias, quase sempre, aparecem entrelaçadas. Antes de apresentar o conceito 
de aspecto, que norteará esta investigação, é preciso apresentar esclarecimentos sobre a categoria tempo. Comrie (1985) atesta que o tempo linguístico determina o tempo da enunciação. Dessa forma, é fundamental recuperar a delimitação dos tempos mais comuns às línguas, sendo eles o presente, o pretérito e o futuro. No tempo presente, a situação é marcada no momento da fala:

(3) Liza está aqui.

No pretérito, a situação é apresentada como um momento anterior à fala:

Liza esteve aqui.

E, por fim, no futuro, a situação é marcada posteriormente à fala:

(5) Liza estará aqui.

O verbo é uma importante classe para a manifestação do tempo e, logo, para a manifestação de aspecto. Castilho (1968) assegura essa importância ao atestar que o sentido expresso pelo verbo "pode ser dimensionado de diferentes formas através das categorias verbais, em número de seis; aspecto, tempo, modo, voz, pessoa e número". (CASTILHO, 1968, p. 13). Além disso, o autor incorpora a dimensão desses conceitos ao apresentar uma definição inicial de aspecto como "uma categoria de natureza léxico-sintática, pois em sua caracterização interagem o sentido que a raiz do verbo contém e elementos sintáticos tais como adjuntos adverbiais, complementos e tipo oracional". (CASTILHO, 1968, p. 14).

Entretanto, o principal elemento que confirma a distinção entre tempo e aspecto é a noção de dêixis, um referente textual que se atualiza de acordo com o contexto. Castro e Hermont (2017, p. 408) sumarizam a distinção ao afirmar que, "ao contrário do tempo, o aspecto é uma categoria não dêitica, já 
que ocorre independentemente de sua relação com o momento da fala". Para complementar o entendimento sobre aspecto, vale enfatizar o sintagma "os diferentes modos", quando Comrie (1976) define aspecto como "os diferentes modos de observar a constituição temporal interna da situação". Isso porque há, na classificação aspectual, duas formas canônicas de observar sua expressão, o aspecto gramatical, que pode ser dividido entre aspecto perfectivo e aspecto imperfectivo; e o aspecto semântico, que pode ser dividido entre télico/atélico, durativo/ pontual e dinâmico/estativo.

Para Castro e Hermont (2017, p. 408), a diferença entre perfectivo e imperfectivo está marcada nas "noções aspectuais codificadas em elementos gramaticais, tais como a flexão verbal e os verbos auxiliares". Para exemplificar, considerem-se as orações:

(6) João esteve no parque.

(7) João estava no parque.

Em (6), é perceptível que o aspecto marcado pelo verbo "esteve", pretérito perfeito do indicativo, é perfectivo, pois, mesmo que não haja a marcação do início da ação, há a ideia expressa de que a situação está finalizada. Conforme será explicado mais adiante, essa expressão está codificada no morfema -Ø- (zero). Em (7), o aspecto expresso pelo verbo "estava", pretérito imperfeito do indicativo, é imperfectivo, pois, além de haver a noção de uma situação que ainda se dá, não há uma demarcação de início ou término dela. Essa expressão está codificada no morfema -va-. No mesmo morfema, encontrase, ainda, a marcação do modo indicativo e do tempo verbal pretérito imperfeito, o que aproxima os VL dos verbos transitivos e intransitivos, por exemplo, pois esse mesmo conjunto de 
expressões está presente em demais verbos do PB.

Em relação ao aspecto semântico, tem-se, conforme introduzido anteriormente, os traços télico/atélico, durativo/ pontual e dinâmico/estativo. Vale ressaltar, neste momento, a noção de telicidade, a qual marca uma situação, ação ou evento que apresenta um fim inerente, e a noção de atelicidade, que marca uma situação, ação ou evento que não apresenta um fim inerente. Esses traços, de acordo com a ordem apresentada, podem ser exemplificados com o VL:

(8) Liza esteve com febre.

(9) João é amigo de Pedro.

(10) Ele continua amigo de Pedro.

(11) Ele esteve ausente na escola ontem.

Nesse sentido, o VL pode ser entendido como marcador tanto de aspecto gramatical, quanto de aspecto semântico. Em relação ao aspecto gramatical, por exemplo, a desinência de modo, tempo e aspecto (DMTA) -ia-, no pretérito imperfeito, em verbos regulares como "parecer", marca o aspecto imperfectivo. A respeito do aspecto semântico, em diferentes contextos oracionais, o VL parece apresentar somente traços atélicos, considerando que ele é um verbo de estado. No entanto, este estudo focará seus esforços na análise do aspecto gramatical que também é conhecido como "aspecto do ponto de vista", porque ele descreve situações a partir de pontos de vistas diferentes.

Na sentença (6), "João esteve no parque”, é possível analisála de um ponto de vista externo, ou seja, de fora da situação, uma vez que ela pode ser compreendida num todo já finalizado em que se pode constatar o seu início e término. Já em (7), “João estava no parque", o imperfectivo, aqui marcado pelo pretérito imperfeito, é analisado sob um ponto de vista interno, quer dizer, a situação é composta por fases e não se pode postular que elas foram finalizadas e que a situação é hoje inexistente. 
Cançado e Amaral (2016, p. 151-152) apresentam um questionamento importante: "Talvez os estados descrevem somente constatações de situações, com marcação de tempo, mas sem marcação de aspecto gramatical. Esse é um ponto que fica em aberto para maiores investigações". Nesse caso, as autoras dizem sobre estados. Vale ressaltar que os VL são verbos de estado, porém nem todos os verbos de estado são verbos de ligação. Traremos aqui o exemplo das autoras:

(12) João teve uma casa na praia.

No exemplo de Cançado e Amaral (2016, p. 151), tem-se um verbo de estado que não é VL. Ainda assim, este trabalho investiu esforços para responder se os VL, como verbos de estado, apenas denotam situações ou marcam aspecto gramatical também, além de tempo. Por fim, faz-se necessário observar os radicais dos VL por duas hipóteses. Primeiramente, porque, ao entender o aspecto gramatical do VL, é imprescindível determinar se o radical será considerado como marcador de aspecto gramatical, uma vez que morfemas serão analisados, e o radical é assim considerado; ou, em uma segunda hipótese, se o radical não marca o aspecto gramatical, já que ele é um morfema lexical e por isso já se entende que, sendo base, por si só, o radical transmite carga semântica.

\section{Caminhos metodológicos adotados: o VL na segmenta- ção morfêmica}

Esta investigação apresenta análises da marcação de aspecto gramatical dos VL como demonstração de que o VL pode não ser uma categoria semanticamente vazia e marcar o aspecto da sentença. Nesse sentido, este artigo tem como 
questão orientadora: de que forma o VL pode ser considerado uma categoria semanticamente realizada, por meio da marcação de aspecto gramatical? O objetivo geral da investigação foi compreender os traços aspectuais contidos no VL. Como objetivos específicos, este artigo se propõe a:

(i) apresentar quadros morfológicas que apontem possíveis expressões aspectuais pelo VL do PB;

(ii) identificar se o VL descreve situações apenas com marcação de tempo ou também de aspecto;

(iii) determinar o papel dos radicais dos VL na marcação de aspecto gramatical.

Neste trabalho, dentre as várias opções metodológicas, optou-se pela abordagem qualitativa, por se entender que seja a mais adequada aos propósitos apresentados, e, como o objetivo, aqui, nesta pesquisa, foi analisar como o VL pode ser semanticamente interpretado por meio de morfemas indicadores de aspecto gramatical, considerou-se a pesquisa bibliográfica como uma abordagem inicial importante.

Nesta seção, também será demonstrado o estudo realizado sobre os morfemas que compõem o VL à luz de uma análise aspectual na qual se busca entender se o aspecto pode estar expresso no radical, na vogal temática (VT), na desinência número e pessoa (DNP), ou apenas na desinência de modo, tempo e aspecto (DMTA), como recorrente na literatura. Além disso, serão exibidos os quadros morfológicos dos verbos "continuar" (regular) e "ser" (anômalo), para auxiliar na identificação aspectual pelos morfemas. Ainda que esta pesquisa tenha produzido um quadro morfológico para cada VL, a saber: ser, estar, continuar, virar, andar, ficar, parecer, permanecer, viver, tornar-se e encontrar-se, devido à extensão deles, optou-se por trazer apenas três. 


\section{Sobre a morfologia dos VL}

Conforme já mencionado anteriormente, esta seção debruçase sobre os estudos da morfologia e, mais especificamente, sobre os morfemas que fazem a composição do VL. Fica em evidência que o estudo da morfologia, além de compreender bastantes segmentos, é extenso e enriquecedor para a análise da expressão aspectual no VL, pois, com ele, é possível examinar divisões das palavras que apresentam significados e podem determinar características específicas sobre elas, como a marcação do aspecto gramatical.

Em relação ao morfema - Ø-, vale dizer que ele constitui uma ausência cujo objetivo é ser condição de oposição entre uma forma marcada contra uma forma não marcada. Como exemplo, analisam-se as palavras "virávamos" e "virava". Sabe-se que ambas, conjugações do VL "virar", fazem parte do pretérito imperfeito. No entanto, na primeira, há a marcação da DNP, enquanto, na segunda, há um morfema - $\varnothing$ - que codifica o singular. Já sobre a DMTA, especificamente no caso dos VL regulares, há marcação regular de modo, tempo e aspecto nos tempos pretérito imperfeito e pretérito mais-que-perfeito, e marcação do morfema -Ø-, nos tempos presente e pretérito perfeito (com exceção da terceira pessoa do plural, que, também, apresenta marcação do morfema -ra-, ou -ve-, no caso do verbo "estar"). Aqui, cabe uma observação: o verbo "estar", no pretérito perfeito, apresenta todas as marcações da DMTA.

\subsection{Análise morfêmica do VL}

Nesta pesquisa, foram analisados os VL nos tempos presente do indicativo $(\mathrm{PI})$, pretérito imperfeito do indicativo 
(PII), pretérito perfeito do indicativo (PPI) e pretérito maisque-perfeito do indicativo ( $\mathrm{P}+\mathrm{QPI})$, todos do modo indicativo. Excluiu-se o tempo futuro e os modos subjuntivo e imperativo, pois não marcam aspecto, já que, nesses modos e nesse tempo, a situação não foi realizada.

O quadro a seguir trará a conjugação do verbo "continuar" e seus morfemas. A partir dele, será feita a análise morfológica com o objetivo de verificar as marcações de aspecto gramatical.

Quadro 1 - Morfologia do verbo "continuar"

\begin{tabular}{|c|c|c|c|c|c|c|}
\hline Tempo & Pessoa & Verbo & Radical & VT & DMTA & DNP \\
\hline Presente & $\begin{array}{l}\text { Eu } \\
\text { Tu } \\
\text { Ele } \\
\text { Nós } \\
\text { Vós } \\
\text { Eles }\end{array}$ & $\begin{array}{l}\text { Continuo } \\
\text { Continuas } \\
\text { Continua } \\
\text { Continuamos } \\
\text { Continuais } \\
\text { Continuam }\end{array}$ & $\begin{array}{l}\text { Continu- } \\
\text { Continu- } \\
\text { Continu- } \\
\text { Continu- } \\
\text { Continu- } \\
\text { Continu- }\end{array}$ & $\begin{array}{l}-\varnothing- \\
-a- \\
-a- \\
-a- \\
-a- \\
-a-\end{array}$ & $\begin{array}{l}-\varnothing- \\
-\varnothing- \\
-\varnothing- \\
-\varnothing- \\
-\varnothing- \\
-\varnothing-\end{array}$ & $\begin{array}{l}-0 \\
-s \\
-\varnothing \\
-m o s \\
-i s \\
-m\end{array}$ \\
\hline $\begin{array}{l}\text { Pretérito } \\
\text { Imperfeito }\end{array}$ & $\begin{array}{l}\mathrm{Eu} \\
\mathrm{Tu} \\
\text { Ele } \\
\text { Nós } \\
\text { Vós } \\
\text { Eles }\end{array}$ & $\begin{array}{l}\text { Continuava } \\
\text { Continuavas } \\
\text { Continuava } \\
\text { Continuávamos } \\
\text { Continuáveis } \\
\text { Continuavam }\end{array}$ & $\begin{array}{l}\text { Continu- } \\
\text { Continu- } \\
\text { Continu- } \\
\text { Continu- } \\
\text { Continu- } \\
\text { Continu- }\end{array}$ & $\begin{array}{l}-a- \\
-a- \\
-a- \\
-a ́- \\
-a ́- \\
-a-\end{array}$ & $\begin{array}{l}\text {-va- } \\
\text {-va- } \\
\text {-va- } \\
\text {-va- } \\
\text {-ve- } \\
\text {-va- }\end{array}$ & $\begin{array}{l}-\varnothing \\
-s \\
-\varnothing \\
-m o s \\
-i s \\
-m\end{array}$ \\
\hline $\begin{array}{l}\text { Pretérito } \\
\text { Perfeito }\end{array}$ & $\begin{array}{l}\mathrm{Eu} \\
\mathrm{Tu} \\
\text { Ele } \\
\text { Nós } \\
\text { Vós } \\
\text { Eles }\end{array}$ & $\begin{array}{l}\text { Continuei } \\
\text { Continuaste } \\
\text { Continuou } \\
\text { Continuamos } \\
\text { Continuastes } \\
\text { Continuaram }\end{array}$ & $\begin{array}{l}\text { Continu- } \\
\text { Continu- } \\
\text { Continu- } \\
\text { Continu- } \\
\text { Continu- } \\
\text { Continu- }\end{array}$ & $\begin{array}{l}-e- \\
-a- \\
-o- \\
-a- \\
-a- \\
-a-\end{array}$ & $\begin{array}{l}-\varnothing- \\
-\varnothing- \\
-\varnothing- \\
-\varnothing- \\
-\varnothing- \\
-r a-\end{array}$ & $\begin{array}{l}-\mathrm{i} \\
- \text { ste } \\
-\mathrm{u} \\
-\mathrm{mos} \\
-\mathrm{stes} \\
-\mathrm{m}\end{array}$ \\
\hline $\begin{array}{l}\text { Pretérito } \\
\text { Mais-que- } \\
\text { Perfeito }\end{array}$ & $\begin{array}{l}\text { Eu } \\
\text { Tu } \\
\text { Ele } \\
\text { Nós } \\
\text { Vós } \\
\text { Eles }\end{array}$ & $\begin{array}{l}\text { Continuara } \\
\text { Continuaras } \\
\text { Continuara } \\
\text { Continuáramos } \\
\text { Continuáreis } \\
\text { Continuaram }\end{array}$ & $\begin{array}{l}\text { Continu- } \\
\text { Continu- } \\
\text { Continu- } \\
\text { Continu- } \\
\text { Continu- } \\
\text { Continu- }\end{array}$ & $\begin{array}{l}-a- \\
-a- \\
-a- \\
-a ́- \\
-a ́- \\
-a-\end{array}$ & $\begin{array}{l}\text {-ra- } \\
\text {-ra- } \\
\text {-ra- } \\
\text {-ra- } \\
- \text { re- } \\
- \text { ra- }\end{array}$ & $\begin{array}{l}-\varnothing \\
-\mathrm{s} \\
-\varnothing \\
-\mathrm{mos} \\
- \text { is } \\
-\mathrm{m}\end{array}$ \\
\hline
\end{tabular}

Fonte: Elaborado pelas autoras. 
O verbo "continuar" é um verbo que apresenta o mesmo radical (continu-) para todas as conjugações e é, portanto, um verbo regular da língua portuguesa (LP). O radical continu- é um elemento mórfico, e a base do significado do verbo aqui analisado remete ao conceito e à expressão de "contínuo" e de não acabado. Nesse caso, o radical denota aspecto semântico atélico.

No tempo presente, a VT, assim como nos demais verbos regulares transitivos e intransitivos da LP, apresenta morfema -Ø- para a primeira pessoa do singular e, para as demais vozes, apresenta -a-. A similaridade entre o VL e as demais tipologias verbais se estende: é característica do tempo presente apresentar morfema -Ø- para todas as pessoas do discurso na DMTA, e o VL atende a essa especificidade. A DNP também não destoa, apresentando os morfemas -o, -s, -Ø, -mos (marca de primeira pessoa do plural), -is e -m, que são comuns aos outros verbos.

No tempo pretérito imperfeito, estão presentes as VT-a-(em quatro vozes verbais) e o alomorfe -á- (em duas vozes verbais). Considerando que, no mesmo morfema, -va-, por exemplo, estão codificados, no modo indicativo, o tempo pretérito e o aspecto imperfectivo, é plausível, e possível, a realização de uma análise aspectual por meio de uma análise morfológica. Ao comparar os tempos presente e pretérito imperfeito, ambos codificados pelo aspecto imperfectivo, é notório que, na DMTA, o tempo presente apresenta morfema -Ø-, enquanto o pretérito imperfeito apresenta os morfemas -va- e -ve-, em que -ve- é um alomorfe de -va-. Nesse tempo, a DNP também não contrasta, apresentando morfemas comuns aos verbos regulares terminados em -ar. Portanto, é possível afirmar que o VL, como verbo de estado, descreve situações e não eventos e atividades. Porém, 
o VL descreve situações com marcação de tempo e também com marcação de aspecto gramatical, assim como os verbos monoargumentais e biargumentais, já que os morfemas - $\varnothing-$-, -vae -ve- são também marcas aspectuais.

Nos tempos pretérito perfeito e mais-que-perfeito, ambos marcadores de aspecto perfectivo, observam-se as VT -e(apenas na primeira pessoa do singular do PPI), -a- (ocorrência em quatro vozes verbais do PPI e, também, em quatro vozes do $\mathrm{P}+\mathrm{QPI}$ ), -o- (apenas na terceira pessoa do singular do PPI) e -á- (ocorrência em duas vozes verbais do P+QPI). Na análise das VT do verbo "continuar", é perceptível como a alomorfia pode ser classificada: verificam-se diversas variações, diversos alomorfes, da VT -a-. Em relação à DMTA, no tempo PPI, há -Øpara todas as vozes verbais, com exceção da terceira pessoa do plural, em que há o morfema -ra-. No tempo P+QPI, os morfemas -ra- e -re-, sendo este um alomorfe de -ra-, expressam as noções de tempo perfeito, modo indicativo e aspecto perfectivo - ao codificar a noção de ação já finalizada. Aqui, a DNP também - como esperado - não diverge do canônico para desinências número-pessoais de verbos regulares terminados em -ar.

Agora, atente-se para o quadro que sumariza a marcação de aspecto gramatical em demais VL, com atenção especial à DMTA. 
Gláucia do Carmo Xavier e Kelly Cesário de Oliveira

Quadro 2 - VL regulares e a marcação de aspecto gramatical

\begin{tabular}{|c|c|c|c|c|c|c|c|}
\hline VL & Radical & VT & $\begin{array}{l}\text { DMTA } \\
(\mathrm{PI})^{1}\end{array}$ & $\begin{array}{l}\text { DMTA }^{2} \\
(\mathrm{PII})\end{array}$ & $\begin{array}{l}\text { DMTA } \\
(\mathrm{PPI})\end{array}$ & $\begin{array}{l}\text { DMTA } \\
(\mathrm{P}+\mathrm{QPI})\end{array}$ & $\begin{array}{l}\text { DNP } \\
(-Ø-)\end{array}$ \\
\hline $\begin{array}{l}\text { Virar, Andar } \\
\text { e Ficar }\end{array}$ & $\begin{array}{l}\text { Vir-, And- } \\
\text {, Fic-, e } \\
\text { Fiqu- }\end{array}$ & $\begin{array}{l}-\varnothing-, \\
-a-, \\
-a ́-, \\
-e- \\
-o-\end{array}$ & $-\varnothing-$ & $\begin{array}{l}\text {-va- e } \\
\text {-ve- }\end{array}$ & $\begin{array}{l}-\varnothing- \\
\text { (com } \\
\text { exceção } \\
\text { da } 3^{\mathrm{a} p} \\
\text { PPI) }\end{array}$ & $\begin{array}{l}\text {-ra- e } \\
\text {-re- }\end{array}$ & $\begin{array}{l}3^{\mathrm{a}} \mathrm{s}(\mathrm{PI}) \\
1 \text { e } 3^{\mathrm{a}} \mathrm{s} \\
(\mathrm{PII}) \mathrm{e} \\
1 \text { e } 3^{\mathrm{a}} \mathrm{s} \\
(\mathrm{P}+\mathrm{QPI})\end{array}$ \\
\hline $\begin{array}{l}\text { Tornar-se e } \\
\text { Encontrar- } \\
\text { se }\end{array}$ & $\begin{array}{l}\text { Torn- e } \\
\text { Encontr- }\end{array}$ & $\begin{array}{l}-\varnothing- \\
-a-, \\
-a ́-, \\
-e- \\
-o-\end{array}$ & $-\varnothing-$ & $\begin{array}{l}\text {-va- e } \\
\text {-ve- }\end{array}$ & $\begin{array}{l}-\varnothing- \\
\text { (com } \\
\text { exceção } \\
\text { da } 3^{\mathrm{a} p} \\
\text { PPI) }\end{array}$ & $\begin{array}{l}\text {-ra- e } \\
\text {-re- }\end{array}$ & $\begin{array}{l}3^{\mathrm{a}} \mathrm{s}(\mathrm{PI}) \\
1 \text { e } 3^{\mathrm{a}} \mathrm{s} \\
(\mathrm{PII}) \mathrm{e} \\
1 \text { e } 3^{\mathrm{a}} \mathrm{s} \\
(\mathrm{P}+\mathrm{QPI})\end{array}$ \\
\hline $\begin{array}{l}\text { Parecer, } \\
\text { Permanecer } \\
\text { e Viver }\end{array}$ & $\begin{array}{l}\text { Parec-, } \\
\text { Permaneç-, } \\
\text { Permanec- } \\
\text { e Viv- }\end{array}$ & $\begin{array}{l}-\varnothing- \\
-e- \\
-e ̂-\end{array}$ & $-\varnothing-$ & $\begin{array}{l}\text {-ia-, } \\
\text {-ía-, } \\
\text {-íe- }\end{array}$ & $\begin{array}{l}-\varnothing- \\
\text { (com } \\
\text { exceção } \\
\text { da } 3^{\mathrm{a} p} \\
\text { PPI) }\end{array}$ & $\begin{array}{l}\text {-ra- e } \\
\text {-re- }\end{array}$ & $\begin{array}{l}3^{\mathrm{a}} \mathrm{s}(\mathrm{PI}), \\
1 \text { e } 3^{\mathrm{a}} \mathrm{s} \\
(\mathrm{PII}), 1^{\mathrm{a}} \mathrm{p} \\
(\mathrm{PPI}) \mathrm{e} \\
1 \text { e } 3^{\mathrm{a}} \mathrm{s} \\
(\mathrm{P}+\mathrm{QPI})\end{array}$ \\
\hline
\end{tabular}

Fonte: Elaborado pelas autoras.

Analisando, primeiramente, a DMTA no tempo presente (PI), percebe-se que esta apresenta -Ø- em todos os verbos. No tempo pretérito imperfeito (PII), os morfemas -va- e -ve(apenas na segunda pessoa do plural) alternam-se em suas devidas pessoas verbais. No tempo pretérito perfeito (PPI), todos os verbos apresentam -Ø-, com exceção da terceira pessoa do plural, cujo morfema é -ra-. Já no tempo pretérito mais-queperfeito, todos os verbos apresentam morfemas -ra- e -re-, sendo o último apenas na segunda pessoa do plural para todos os VL regulares.

Sobre a DMTA no modo presente, como marca desse tempo, os verbos apresentam - $\varnothing$-. No tempo pretérito imperfeito, os verbos apresentam os morfemas -ia- (primeira, segunda e terceira pessoas do singular e na terceira pessoa do plural), -ía(na primeira pessoa do plural) e-íe-(apenas na segunda pessoa do 
plural). No tempo pretérito perfeito, todos os verbos relacionados na tabela apresentam - $\varnothing$ - em todas as pessoas do discurso, com exceção da terceira pessoa do plural, cujo morfema é -ra- para todos os verbos. No tempo pretérito mais-que-perfeito, todos os verbos apresentam morfemas -ra- e -re- (sendo o último apenas na segunda pessoa do plural dos verbos relacionados). Relativamente à DNP desses verbos, é perceptível a semelhança entre o VL e os demais verbos terminados em -ar e -er, pois eles apresentam morfemas conforme a literatura postula, como -o, -s, -Ø, -mos, -i, -is, -m, -ste e -stes em suas determinadas vozes verbais.

Em síntese, a partir de uma análise morfológica completa do VL, é possível afirmar que verbos terminados em -ar, em todos os tempos verbais analisados, como "continuar", "virar", "andar", "ficar", até "tornar-se" e "encontrar-se", aproximam-se de verbos monoargumentais e biargumentais regulares do PB, no que tange à área da morfologia. Isso porque os VL apresentam a mesma estrutura para a segmentação morfêmica e, da mesma forma que verbos plenos regulares apresentam morfemas para aspecto gramatical, o VL também. Essa mesma conclusão pode ser válida para verbos terminados em -er, como "parecer", "permanecer", "viver" e, de certa forma, também para o verbo "ser" - como será visto posteriormente. Tais semelhanças constroem uma similaridade entre esses VL e os demais verbos da LP no que se refere à marcação de aspecto gramatical.

No entanto, os verbos "ser" e "estar" denotam diferenças, de forma especial no radical e na carga semântica que carregam, que podem influenciar na análise aspectual. Vejamos.

As diferenças sintáticas constatadas entre ser e estar constituem um dos mais desafiadores problemas da língua portuguesa, maiormente quando a comparamos 
às línguas românicas. Esses verbos constituem um complicador também no ensino do português como língua estrangeira. [...] Ser é um verbo de etimologia complexa. Três radicais latinos confluíram em sua conjunção. [...] Estar deriva de uma única etimologia. (CASTILHO, 2014, p. 397, 399, grifo do autor).

Conforme Castilho (2014), o verbo "ser" pode denotar propriedade permanente, enquanto o verbo "estar" denota propriedade transitória quando valida o sujeito apenas por certo período de tempo, ou seja, a duração demonstra falta de intervalos, como em:

(13) Liza é estudiosa.

(14) Liza está estudiosa.

Lemos (1987) aborda outra questão pertinente para a análise do aspecto dos verbos "ser" e "estar". Ela afirma que, quando usamos "estar", estamos focalizando o falante e o ouvinte com a descrição de uma situação em que os dois participam. Já o verbo "ser" denota que os participantes da cena linguística ficam externos ao ângulo de visão. Esse posicionamento de Lemos se justifica na medida em que ela defende que a visão exerce uma função imprescindível na organização gramatical. Nesse sentido, não é gramatical dizer:

(15) João será na escola hoje.

Entretanto, é gramatical:

(16) João estará na escola hoje.

Essa diferença demonstra um traço de (+) ou (-) dinamicidade que vem da própria etimologia desses dois VL. Assim, o conjunto de traços do verbo "ser" de (-) dinâmico e $(+)$ permanente e do verbo "estar" como $(+)$ dinâmico e $(+)$ transitório implica o aspecto gramatical, uma vez que as noções de telicidade corroboram para a ocorrência da perfectividade 
com mais frequência, assim como as noções de atelicidade corroboram para a ocorrência da imperfectividade. Xavier (2019) reforça essa ideia:

Afirma-se que, de fato, os verbos télicos tendem a ser
mais perfectivos, como foi verificado na pesquisa com
320 dados. No entanto, essa afirmação pode variar
conforme o contexto e o campo semântico dos verbos
analisados. Já os verbos atélicos são certamente mais
imperfectivos independentemente de qualquer variável,
como contexto ou campo semântico dos verbos em uma
amostra. (XAVIER, 2019, p. 195).

Sobre a relevância de que a visão, como órgão de sentido, exerce papel fundamental na gramática, isso pode ser verificado em sentenças como:

(17) A escola está na praça.

É possível afirmar essa importância da visão nos estudos gramaticais, pois se pressupõe a ideia de que o falante precisa se locomover para algum lugar. Por outro lado, tem-se:

(18) A escola é na praça.

Em (18), o verbo denota apenas situação, sem necessidade de locomoção. Essas sentenças apresentam duas considerações: em primeiro lugar, a de que sujeitos gramaticais com traço de $(+)$ humano e/ou $(+)$ animado não formam sentenças gramaticais com ideia de movimento, a partir do verbo "ser". "Estar assentado" é gramatical, mas "ser assentado" não é. Em segundo lugar, a consideração de que, para sujeitos gramaticais com traço de (-) humano e/ou (-) animado, o verbo "estar" dá noção de necessidade do falante de se movimentar, enquanto o verbo "ser" apenas mostra os participantes da cena linguística como algo fora do campo de visão, como em

(19) A churrasqueira está fora da casa. 
(20) A churrasqueira é fora da casa.

(21) A TV está no quarto.

(22) A TV é no quarto.

Somado a isso, vale dizer que o radical do verbo "ser" surge de essere, da forma vulgar do latim que influenciou as formas do PB “sou, somos, sois, são, é, és e era"; da forma sedere, que faz surgir "seja, serei, seria, sê, sede, sendo, sido e ser"; além do ire, que dá origem a "fui, foste, foi, fomos, fostes, foram, fora, fosse e for". A anomalia de "ser", então, é justificada pelas alterações profundas sofridas pelo radical, apresentando, em sua conjugação, diferentes alomorfes, como -s-, -f- e -e-.

Já o verbo “estar", embora não apresente alteração no radical - forte característica para identificar verbos irregulares - sofre alterações em suas desinências do tempo pretérito mais-que-perfeito. "Estar" apresenta morfemas como "véra" e "ramos" para a primeira pessoa do plural no pretérito mais-queperfeito, o que não é encontrado em verbos monoargumentais.

O quadro morfológico do verbo "ser", abaixo, demonstra bem a inconstância do radical. 
Marcação de aspecto gramatical nos verbos de ligação: uma análise morfológica

\begin{tabular}{|c|c|c|c|c|c|c|}
\hline \multicolumn{7}{|c|}{ Quadro 3 - Morfologia do verbo "ser" } \\
\hline Tempo & Pessoa & Verbo & Radical & VT & DMTA & DNP \\
\hline Presente & $\begin{array}{l}\text { Eu } \\
\text { Tu } \\
\text { Ele } \\
\text { Nós } \\
\text { Vós } \\
\text { Eles }\end{array}$ & $\begin{array}{l}\text { Sou } \\
\text { És } \\
\text { É } \\
\text { Somos } \\
\text { Sois } \\
\text { São }\end{array}$ & $\begin{array}{l}\text { S- } \\
\text { é- } \\
\text { é- } \\
\text { S- } \\
\text { S- } \\
\text { S- }\end{array}$ & $\begin{array}{l}-0- \\
-\varnothing- \\
-\varnothing- \\
-0- \\
-0- \\
-\tilde{a}-\end{array}$ & $\begin{array}{l}-\varnothing- \\
-\varnothing- \\
-\varnothing- \\
-\varnothing- \\
-\varnothing- \\
-\varnothing-\end{array}$ & $\begin{array}{l}-u \\
-s \\
-\varnothing- \\
-m o s \\
-i s \\
-o\end{array}$ \\
\hline $\begin{array}{l}\text { Pretérito } \\
\text { Imperfeito }\end{array}$ & $\begin{array}{l}\text { Eu } \\
\text { Tu } \\
\text { Ele } \\
\text { Nós } \\
\text { Vós } \\
\text { Eles }\end{array}$ & $\begin{array}{l}\text { Era } \\
\text { Eras } \\
\text { Era } \\
\text { Éramos } \\
\text { Éreis } \\
\text { Eram }\end{array}$ & $\begin{array}{l}\text { e- } \\
\text { e- } \\
\text { e- } \\
\text { é- } \\
\text { é- } \\
\text { e- }\end{array}$ & $\begin{array}{l}-\varnothing- \\
-\varnothing- \\
-\varnothing- \\
-\varnothing- \\
-\varnothing- \\
-\varnothing-\end{array}$ & $\begin{array}{l}\text {-ra- } \\
\text {-ra- } \\
\text {-ra- } \\
\text {-ra- } \\
\text {-re- } \\
\text {-ra- }\end{array}$ & $\begin{array}{l}-a \\
-s \\
-a \\
-m o s \\
-i s \\
-m\end{array}$ \\
\hline $\begin{array}{l}\text { Pretérito } \\
\text { Perfeito }\end{array}$ & $\begin{array}{l}\text { Eu } \\
\text { Tu } \\
\text { Ele } \\
\text { Nós } \\
\text { Vós } \\
\text { Eles }\end{array}$ & $\begin{array}{l}\text { Fui } \\
\text { Foste } \\
\text { Foi } \\
\text { Fomos } \\
\text { Fostes } \\
\text { Foram }\end{array}$ & $\begin{array}{l}f- \\
f- \\
f- \\
f- \\
f- \\
f-\end{array}$ & $\begin{array}{l}-\mathrm{U}- \\
-\mathrm{O}- \\
-\mathrm{O}- \\
-\mathrm{O}- \\
-\mathrm{O}- \\
-\mathrm{O}-\end{array}$ & $\begin{array}{l}-\varnothing- \\
-\varnothing- \\
-\varnothing- \\
-\varnothing- \\
-\varnothing- \\
-r a-\end{array}$ & $\begin{array}{l}-\mathrm{i} \\
- \text { ste } \\
-\mathrm{i} \\
-\mathrm{mos} \\
\text {-stes } \\
-\mathrm{m}\end{array}$ \\
\hline $\begin{array}{l}\text { Pretérito } \\
\text { Mais-que- } \\
\text { Perfeito }\end{array}$ & $\begin{array}{l}\text { Eu } \\
\text { Tu } \\
\text { Ele } \\
\text { Nós } \\
\text { Vós } \\
\text { Eles }\end{array}$ & $\begin{array}{l}\text { Fora } \\
\text { Foras } \\
\text { Fora } \\
\text { Fôramos } \\
\text { Fôreis } \\
\text { Foram }\end{array}$ & $\begin{array}{l}f- \\
f- \\
f- \\
f- \\
f- \\
f-\end{array}$ & 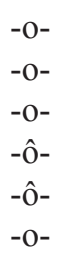 & $\begin{array}{l}\text {-ra- } \\
\text {-ra- } \\
\text {-ra- } \\
\text {-ra- } \\
\text {-re- } \\
\text {-ra- }\end{array}$ & $\begin{array}{l}-\varnothing- \\
\mathrm{s} \\
-\varnothing- \\
\mathrm{mos} \\
\text { is } \\
\mathrm{m}\end{array}$ \\
\hline
\end{tabular}

Fonte: Elaborado pelas autoras.

Considerando que o verbo "ser" pode ser analisado como um verbo de segunda conjugação, assume-se, a partir de uma comparação entre "ser" e "parecer", "permanecer" e "viver", uma semelhança lógica entre esses quatro verbos. Observandose a VT, o verbo "ser" se assimila aos demais, com exceção das marcações realizadas nos tempos presente, pois a segunda e a terceira pessoas do singular apresentam - $\varnothing$-; e o pretérito perfeito, que apresenta - $u$ - na primeira pessoa do singular, enquanto os demais apresentam - $\varnothing$-. 
Na DMTA, o verbo "ser" não difere dos demais nos tempos presente (apresenta -Ø-), pretérito perfeito (apresenta -Ø- e, apenas na terceira pessoa do plural — como os demais - , -ra-) e pretérito mais-que-perfeito (apresenta os morfemas -ra- e -re-). A diferença, nessa categoria, se faz notável no tempo pretérito imperfeito, em que "ser" apresenta os morfemas -ra- e -re-, enquanto os demais apresentam -Ø-.

Em relação à DNP, “ser” apresenta as mesmas configurações morfológicas para os tempos pretérito perfeito e pretérito maisque-perfeito que os demais verbos terminados em -er. Essas diferenças são observadas nos tempos presente, ao apresentar -Øpara a terceira pessoa do plural (enquanto os demais apresentam -m), e pretérito imperfeito, ao não apresentar - $\varnothing$ - para primeira e terceira pessoas do singular. Nesse sentido, conclui-se que "ser" tem diferentes alomorfes em seu radical, e essa é a maior característica que o classifica como verbo anômalo.

Por conseguinte, segundo o Quadro 3, que foi criado a partir de um exercício lógico, através da comparação entre "ser" e os demais VL terminados em -er e, também, por meio da distribuição coesa de morfemas em suas possíveis desinências (por exemplo, não é possível classificar o morfema -mos como DMTA, mas apenas como DNP), confirma-se que "ser", apesar de possuir diferenças na VT e nas desinências de modo, tempo e aspecto e de número e pessoa, possui diversas semelhanças com os verbos "parecer", "permanecer" e "viver". Além disso, essa forma verbal, numa análise sintática, segundo Castilho (2014), indica que o verbo "ser" "tem um único argumento posposto", como em:

(23) Liza é estudiosa.

Sobre a estrutura sintática de sentenças com VL e os 
argumentos pospostos, Xavier, Kenedy e Oliveira (2018) afirmam que os VL selecionam uma small clause e que, para o sujeito ocupar a posição de especificador de sintagma temporal (TP) e receber traços de flexão e caso nominativo, apenas o AdjP (sintagma adjetival) da small clause permanece posposto aos VL, conforme mostra a figura abaixo. Vale ressaltar que essa nova estrutura se difere, pois não traz um sintagma verbal para acomodar VL e, sim, um sintagma aspectual. Isso reforça a ideia de que a compreensão de semanticamente vazio diz respeito à falta de significado lexical, e não a uma noção de semanticamente vazio no que se refere à informação aspectual no momento da derivação da sentença.

\section{Figura 1 - Representação sintática do Verbo de Ligação}

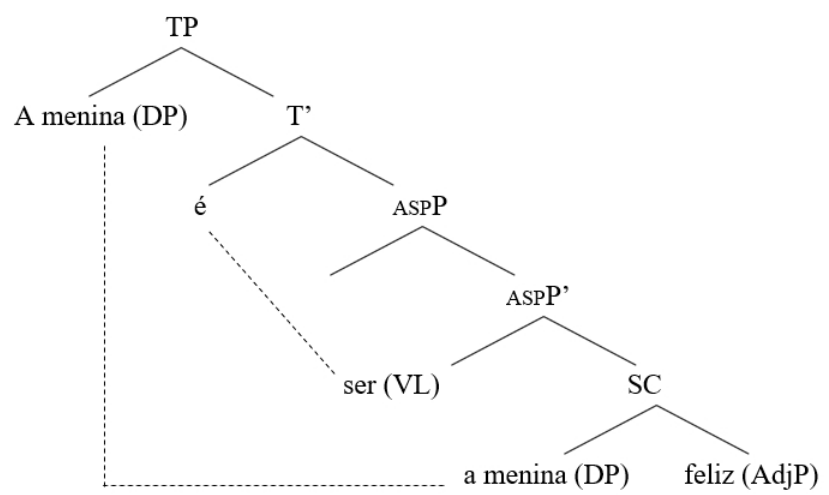

Fonte: Xavier, Kenedy e Oliveira (2018, p. 135).

Como se nota, a anomalia do radical de "ser" dá a esse verbo um status de diferença também no sentido (XAVIER; OLIVEIRA, 2020). Essa é uma das características que julga o verbo "ser" o único verbo de cópula, e não todos os demais VL. Xavier, Kenedy e Oliveira (2018) detalham, em seu trabalho, 
essa justificativa, porém, aqui, vale observar apenas que o verbo "ser", diferentemente dos outros verbos de ligação, pode ser identificado como verbo de cópula e ser compreendido como "vazio de sentido, e disso prova o fato de algumas línguas quase não o usarem com essa função meramente copulativa, isto é, de unir um adjetivo a um substantivo dizendo apenas 'Pedro bom', em vez de "Pedro é bom"'. (ALMEIDA, 2009, p. 239). Essa afirmação impõe ao verbo "ser" uma condicional de necessidade para interpretação da sentença; já o verbo "está", com sua semântica de transitoriedade, de existência momentânea e de estado acidental, demonstra comportamento sintático distinto e aspecto imperfectivo, como em:

(24) Pedro está bom.

A inserção desse verbo "está" abarca a ideia de que Pedro não era bom, mas agora está, a ideia de transitoriedade continua, mesmo se o verbo estiver no pretérito perfeito, como em:

(25) Pedro esteve bom.

Portanto, para além da DTMA, o radical, como um morfema, também indica aspecto gramatical de imperfectividade com os verbos "ser" e "estar", de forma mais acentuada, assim como "continuar", "virar" e "tornar-se".

\subsection{Análise do radical como marcação de aspecto gramatical no VL}

Na seção anterior, foi dada mais atenção aos verbos "ser" e "estar". Neste momento, serão tratados os radicais dos verbos "continuar", "virar" e "tornar-se", os quais apresentam radicais com carga semântica mais expressiva. Dessa forma, é importante verificar se o radical, em um estudo morfêmico, considerado 
como morfema lexical, pode ser entendido como indicador de aspecto gramatical, uma vez que comumente as desinências é que cumprem esse papel, já que elas são chamadas de morfemas flexionais.

No caso de "continuar", o radical continu- carrega carga semântica de atelicidade com a ideia de contínuo. Já os verbos "virar" e "tornar-se" também carregam forte carga semântica nos radicais vir- e torn-, porém com aspecto de perfectividade. Independentemente do tempo verbal, ou seja, mesmo o verbo estando no presente ou pretérito imperfeito, as conjunções dos verbos "virar" e "tornar-se" indicam telicidade. Esses dois verbos indicam sempre, independentemente do tempo verbal, uma situação inceptiva, por apresentar a situação no seu ponto inicial. Assim, eles marcam mudança de estado, o que dá ideia de telicidade.

Portanto, em um estudo morfêmico, encontram-se os seguintes encaminhamentos para a análise dos VL: (1) considerando o radical um morfema e tomando que há nele carga aspectual acentuada de $(+)$ dinamicidade e $(+)$ transitoriedade ou de mudança de estado, pode-se afirmar que o estudo dos morfemas do VL indica marcação de aspecto gramatical; (2) as desinências de modo, tempo e aspecto, com morfemas -vae -ve-, indicam aspecto imperfectivo, já os morfemas -ra- e -re- indicam aspecto perfectivo; (3) o -Ø- é uma característica dos tempos presente e pretérito perfeito, da mesma forma que -Ø- é característica do singular em contraste com verbos no plural. Ou seja, enquanto a posição da DMTA é preenchida no pretérito imperfeito, por exemplo, por -va- e -ve-, nos tempos presente e pretérito perfeito essa posição é preenchida por -Ø-, da mesma forma que há um -Ø- marcando a DNP de "casa" e 
há um morfema -s marcando a DNP de "casas". Portanto, esta investigação defende que o aspecto gramatical dos VL pode ser observado por meio das desinências (DMTA) e do radical, mas não na VT e DNP.

\section{Considerações finais}

Conforme exposto na Introdução deste trabalho, as reflexões e considerações acerca do aspecto gramatical do VL foram diluídas ao longo do texto. Dessa forma, esta seção final retomará apenas os objetivos de pesquisa e seus resultados pontuais. Assim, considerando que a questão norteadora foi compreender os traços aspectuais contidos no VL, como forma de verificar se ele carrega traço semântico, esta pesquisa assume o posicionamento de que o VL indica aspecto, já que a compreensão de semanticamente vazio diz respeito à falta de significado lexical, logo não pode ser considerado semanticamente vazio no que se refere à informação aspectual ou mesmo semanticamente vácuo por não ser considerado na computação semântica, como visto na Figura 1. Outro argumento é que, além de a DMTA determinar aspecto gramatical, o VL apresenta o radical como morfema que carrega carga semântica. Como este estudo focalizou a análise de morfemas e o radical, como tal, é marcador de aspecto, o VL pode determinar aspecto na sentença.

Como objetivos específicos, este artigo se propôs a (i) apresentar tabelas morfológicas que apontem possíveis expressões aspectuais pelo VL do PB; (ii) identificar se o VL descreve situações apenas com marcação de tempo ou também de aspecto; e (iii) determinar o papel dos radicais dos VL na marcação de aspecto gramatical. As pesquisadoras concluíram 
que o VL guarda similaridades com os verbos monoargumentais e biargumentais no que tange ao estudo morfêmico e marcação de DMTA, pois os VL apresentam a mesma estrutura para a segmentação morfêmica e, assim como verbos plenos regulares, apresentam também morfemas para aspecto gramatical, uma vez que os morfemas -Ø-, va- e -ve- são igualmente marcas aspectuais.

Sobre os radicais dos VL, o estudo analisou os verbos "ser" e "estar" separadamente dos demais. O "ser" apresenta traços de (-) dinâmico e $(+)$ permanente, e o verbo "estar" se mostra como $(+)$ dinâmico e $(+)$ transitório. Essa característica reforça o argumento de que as noções de aspecto presentes no morfema lexical, no caso, o radical, influenciam na marcação de aspecto gramatical, já que a marcação dessa categoria ocorre por meio de morfemas. Dessa maneira, como já foi dito, para além da DMTA, o radical, como um morfema, também indica aspecto gramatical de imperfectividade com os verbos "ser", "estar" e "continuar", de forma mais acentuada. Já com os verbos "virar" e "tornar-se", o radical indica telicidade, pois marca mudança de estado e apresenta ideia de inceptividade. Portanto, esta investigação defende que o aspecto gramatical dos VL pode ser observado por meio das desinências (DMTA) e do radical em uma análise morfêmica.

\section{Referências}

ALMEIDA, Napoleão Mendes de. Gramática metódica da língua portuguesa. 46. ed. São Paulo: Saraiva, 2009.

CANÇADO, Márcia; AMARAL, Luana. Introdução à Semântica Lexical: papéis temáticos, aspecto lexical e 
decomposição de predicados. Petrópolis, RJ: Vozes, 2016.

CASTILHO, Ataliba de. Introdução ao Estudo do Aspecto Verbal. 1968. Tese (Doutorado). Marília: Faculdade de Filosofia, Ciências e Letras, 1968.

CASTILHO, Ataliba de. Nova gramática do português brasileiro. São Paulo: Contexto, 2014.

CASTRO, Gisely Gonçalves de; HERMONT, Arabie Bezri. A relação entre o aspecto lexical e o aspecto gramatical em contexto de aquisição da linguagem. Percursos Linguísticos (UFES), v. 7, 2017.

CHOMSKY, Noam. The minimalist program. Cambridge: MIT Press, 1995.

COMRIE, Bernard. Aspect. Cambridge: Cambridge University Press, 1976.

COMRIE, Bernard. Tense. Cambridge: Cambridge University Press, 1985.

LEMOS, Cláudia Tereza Guimarães de. Ser and estar in Brazilian Portuguese with particular reference to child language acquisition. Tubingen: Gunter Narr, 1987.

SANCHEZ-MENDES, Luciana. A modificação de grau em Karitiana. 2014. Tese (Doutorado em Semiótica e Linguística Geral) - Faculdade de Filosofia, Letras e Ciências Humanas, Universidade de São Paulo, São Paulo, 2014.

XAVIER, Gláucia do Carmo. O aspecto verbal sob a ótica da Teoria Gerativa. Curitiba: CRV, 2019.

XAVIER, Gláucia do Carmo; KENEDY, Eduardo; OLIVEIRA, Kelly de. Estudo formal dos verbos de ligação: natureza sintática e representação no módulo mental. Cadernos CESPUC de Pesquisa Série Ensaios, n. 33, p. 112-139, dez. 2018.

XAVIER, Gláucia do Carmo; OLIVEIRA, Kelly Cesário de. Natureza sintática dos verbos de ligação: da derivação 
à representação no módulo mental. In: CONFERÊNCIA LINGUÍSTICA E COGNIÇÃO: DIÁlOGOS IMPRESCINDÍVEIS, 9., 2020, Belo Horizonte. Anais... Belo Horizonte: PUC Minas, 2020.

\section{(Footnotes)}

$1 \mathrm{PI}=$ presente do indicativo, $\mathrm{PII}=$ pretérito imperfeito do indicativo, $\mathrm{PPI}=$ pretérito perfeito do indicativo e $\mathrm{P}+\mathrm{QPI}=$ pretérito mais-que-perfeito do indicativo.

2 DMTA $=$ desinência de modo, tempo e aspecto; DNP = desinência de número e pessoa 